\title{
1 Comparison of the performance of hydraulic lime- and clay-based grouts in
}

\section{2 the repair of rammed earth}

3 Rui A. Silva ${ }^{1}$, Oriol Domínguez-Martínez ${ }^{2}$, Daniel V. Oliveira ${ }^{3}$, Eduardo B. Pereira ${ }^{4}$

$4 \quad{ }^{1,3-4}$ ISISE, University of Minho, Guimarães, Portugal

$5 \quad 2$ Terrachidia Association, Madrid, Spain

6 Abstract:

7 Earth constructions constitute an important part of the built heritage and are spread worldwide. Rammed earth is 8 among the most used earth construction techniques, though it exhibits a high seismic vulnerability. Nevertheless, 9 the structural behaviour of rammed earth structures is still insufficiently comprehended. Thus, the preservation 10 of this built heritage requires exhaustive characterisation of its mechanical and structural behaviours, as well as 11 the development and validation of adequate intervention solutions. In this context, this paper presents an 12 experimental program aimed at evaluating the effectiveness of grout injection to repair cracks and at further 13 characterising the in-plane shear behaviour of rammed earth walls. The experimental program included the 14 testing of rammed earth wallets under diagonal compression, which were subsequently repaired with injection of 15 a clay-based or a hydraulic lime-based grout, and retested. Furthermore, sonic tests were conducted on the 16 wallets before the destructive tests. The obtained results allowed to highlight that both grouts led to similar repairing performances, though the interlocking contribution promoted by the coarse particles of the rammed 18 earth to the shear behaviour was found to be irrecoverable.

20 Keywords: Rammed earth; grout injection; clay-based grout; lime-based grout; repair; shear behaviour; diagonal 21 compression; digital image correlation; sonic testing.

${ }^{1} \mathrm{PhD}$, Post-doc researcher, ISISE, University of Minho, Department of Civil Engineering, Azurém, P-4800-058 Guimarães, Portugal. Phone: +351 253510 200, fax: +351 253510 217, email: ruisilva@civil.uminho.pt ${ }^{2}$ Cofounder, Terrachidia Association, Madrid, Spain, email: oriol.arq@gmail.com ${ }^{3} \mathrm{PhD}$, Associate professor, ISISE, University of Minho, Department of Civil Engineering, Azurém, P-4800-058 Guimarães, Portugal. Phone: +351253510 200, fax: +351253510 217, email: danvco@civil.uminho.pt

${ }^{4} \mathrm{PhD}$, Assistant professor, ISISE, University of Minho, Department of Civil Engineering, Azurém, P-4800-058 Guimarães, Portugal. Phone: +351253510 200, fax: +351 253510 217, email: eduardo.pereira@civil.uminho.pt 


\section{Highlights:}

24 - The behaviour of rammed earth was investigated under compression and shear loading;

25 - The repair effectiveness of clay- and lime-based grouts was compared;

26 - The clay- and lime-based grouts present similar repair performance;

27 - The injection repair was unable to recover the interlocking of the coarse particles;

28 - Sonic tests were not sufficiently sensitive to evaluate the repair effectiveness of injection.

29 


\section{INTRODUCTION}

Raw earth has been widely used around the World as a building material [1]. In developing countries, it is still used intensively to build shelter, though in developed countries its current use is marginal [2]. An important earth built stock is spread worldwide and is estimated to house one-fifth to one-third of the World's population [1][3][4]. The concept of building with raw earth is strongly related to the concept of vernacular architecture [2][5], meaning that several building techniques were developed through time according to local factors [3]. Nevertheless, adobe masonry and rammed earth are frequently depicted as the most popular earth construction techniques [1], which constitute a large majority of the earthen built stock. Adobes are sundried units made of wet earth moulded inside a timber mould, which are layered with earth mortar to build walls, arches, vaults and domes [6]. Building with rammed earth consists in compacting moist earth by layers inside a removable formwork to build monolithic walls. The traditional building process consists in the compaction of large dimension blocks, where the formwork is supported directly on the wall. After the conclusion of a block, the formwork is dismounted and moved horizontally. With the conclusion of a lift, the formwork is moved upwards and mounted with mismatched vertical joints, and then the process is repeated until the desired height of the wall is achieved [7].

Similarly to adobe, rammed earth constructions are also acknowledged to present high seismic vulnerability, which is mainly attributed to poor connections between structural elements, high self-weight and low mechanical properties [8]. The fact is that the recent earthquakes of Bam 2003, Pisco 2007 and Maule 2010 demonstrated the high seismic vulnerability of this type of constructions, where life and economic losses were catastrophic. This limitation of rammed earth construction is of particular concern in the case of southern Portugal [9], namely in Alentejo and Algarve regions. The built heritage in these regions is comprised of a high percentage of rammed earth buildings [10][11], though their integrity and the life of their inhabitants are continuously menaced by a moderate seismic hazard [12].

During an earthquake, rammed earth walls can be subjected to in-plane shear and out-of-plane bending loadings, meaning that the seismic performance of the building is mainly governed by the response of the walls to these actions. Precisely, the few research on the seismic behaviour of rammed earth constructions has been mainly conducted with respect to the experimental characterisation of the in-plane and out-of-plane behaviours. The inplane shear behaviour has been mainly characterised by means of triaxial shear tests, triplet tests [13], diagonal compression tests on wallets [5][14] and cyclic shear-compression tests on walls [15][16][17]. These tests have shown that the shear behaviour of unstabilised rammed earth walls is governed by binding forces due to capillary 
61 suction originated at the porous structure of the material (to which greatly contributes the presence of clay) [18], as well as by the friction and interlocking capacity of the coarse particles. In the case of stabilised rammed earth, the role of the suction forces with respect to the binding mechanisms of the cementitious gels decreases with increasing percentage of the stabiliser. The layered structure of rammed earth was also evidenced to have participation in the shear behaviour, as local sliding failure along the interfaces was observed in some cases [15][17]. The out-of-plane bending of rammed earth has been also investigated at different scales, namely by means of four-point bending tests on beams [19], airbag bending tests on panels [20] and overturning tests on walls [8]. Here, the interfaces were also shown to constitute weak points, as failure tended to occur at these surfaces due to lower tensile strength values in comparison with those of the material within the layer. Rammed earth constructions from southern Portugal are often found in poor conservation condition [11][21], which contributes to increasing their seismic vulnerability [22]. The integrity of rammed earth constructions is disturbed by several weathering agents, namely the action of water (e.g. in the form of rainfall, rising damp and freeze-and-thaw cycles), wind, solar radiation and environmental chemicals (e.g. salts and acid rain) [23][24]. The integrity of rammed earth materials is also affected by excessive loads transmitted by the roof and pavements, as well as by those originated by settlement of foundations and seismic activity [25]. For instance, local crushing of rammed earth walls may occur due to elements of the roof supported directly by the rammed earth, while cracking may occur due to horizontal thrusts applied by the roof or vaulted ceilings/pavements. Cracks constitute preferential paths for rainfall infiltration, which facilitate the increase of the moisture content in the material [23], leading to a substantial reduction of the mechanical properties of rammed earth [26]. The structural capacity and stiffness of rammed earth constructions is also reduced by the presence of important cracks, since they disrupt the monolithic behaviour of the walls and of the overall structure. As a consequence, weathering and excessive loading may compromise seriously the durability of rammed earth constructions and lead to a decrease of their structural performance. The aforementioned context justifies the need for adopting adequate intervention techniques [23][27] able to reinstate the bond disrupted by cracks and to mitigate the exposure to moisture ingress. In general, cracks can be repaired using different techniques, such as filling the gap with mortar and stitching, although their effectiveness and intrusiveness are questionable [25][28]. In turn, the repairing of cracks in earthen materials with grout injection was shown to be an efficient solution [29][30], where the fulfilling of compatible requirements was deemed as a key feature [31]. This requirement led to the development of clay-based grouts, instead of the use of 
in the literature regarding adobe masonry structures, being the grouts stabilised with cement or lime [38][39].

Unstabilised clay-based grouts were also comprehensively investigated with respect to their rheology, strength and adhesion [40], and were adopted for repairing laboratory adobe models tested on shaking table [41] or under lateral loading [42]. The results showed that injection repair with clay-based grouts achieves only partial recovery of the initial structural stiffness and load-bearing capacity of the models. Nevertheless, a significant strength recovery (higher than 90\%) was observed in Illampas et al. [42], where an additional improvement of the connection between the walls and the roof was also reported. The repair of cracks in rammed earth with injection of unstabilised clay-based grouts was also addressed in Silva et al. [14], where repaired wallets tested under diagonal compression reached a satisfactory recovery of the shear strength, but the recovery to the initial shear stiffness was not possible. A drawback of clay-based grouts was reported with respect to its laborious preparation process, which required sieving fine particles of the soil used originally in the construction. In this regard, lime-based grouts, initially deemed as less compatible materials, seem to offer a more practical solution, as they are readily accessible in the market at affordable costs. Nevertheless, the lime-based grout proposed in Müller et al. [43] has shown low performance when used to repair cracks in cob walls. Thus, the injection technique seems to present low performance when used to repair monolithic earthen materials, such as rammed earth, though the doubt remains whether this is an intrinsic aspect of the technique or if it depends on the type of grout used.

109 An experimental program was carried out with the main objective of comparing the effectiveness of the use of clay- and lime-based grouts to repair cracks in rammed earth. The comparison was performed by means of

111 destructive diagonal compression tests and non-destructive sonic tests on rammed earth wallets. Furthermore, the diagonal compression tests were also aimed at better describing the initial and repaired shear behaviour of the

113 specimens, using the digital image correlation (DIC) technique to document the cracking evolution at the surface 114 during the loading sequences.

\section{EXPERIMENTAL PROGRAM}

117 The experimental program involved the execution of diagonal compression tests on wallets representative of

118 unstabilised rammed earth walls from Alentejo region. Each wallet was subjected to a first diagonal compression testing sequence, being subsequently repaired and tested again under diagonal compression. Sonic tests were 
120

121

122

123

124

125

126

127

128

129

130

131

132

133

134

135

136

137

138

139

140

141

conducted additionally to evaluate the effectiveness of the injection repair. The manufacturing of the specimens, testing procedures and grout injection repair are detailed in the subsequent sections.

\subsection{Manufacturing of the specimens}

Six rammed earth wallets were manufactured using soil collected from Alentejo (Southern Portugal). This soil was previously studied in Silva et al. [14] and deemed as presenting excessive clay content, meaning that its particle size distribution required correction by addition of coarse aggregates. The final mixture consisted of $50 \%$ of soil, $28 \%$ of river sand and $22 \%$ of gravel. The particle size distribution curves [44] of the soil mixture and respective components are presented in Fig. 1. Furthermore, the soil mixture presented a liquid limit (LL) of $23 \%$, plastic limit (PL) of $16 \%$, plasticity index (PI) of $7 \%$ [45], and standard Proctor maximum dry density $\left(\rho_{\text {dmax }}\right)$ of $2100 \mathrm{~kg} / \mathrm{m}^{3}$ at optimum water content (OWC) of $10.1 \%$ [46]. The wallets were built with dimensions of 550x550x200 $\mathrm{mm}^{3}$ and using a procedure similar to that described in Silva et al. [14], where the water content was defined according to the drop ball test [47] instead of the OWC, since the former was assumed for practical reasons. The compaction of the wallets was performed in 9 layers by controlling the mixture weight and thickness (about $61 \mathrm{~mm}$ ) in order to theoretically achieve a dry density of the wallets identical to that of the wallets tested in Silva et al. [14], namely $2025 \mathrm{~kg} / \mathrm{m}^{3}$. The actual dry density of the wallets was computed considering their dimensions after compaction, total mass of compacted soil mixture and the water content [48]. The average dry density was found to be slightly higher $\left(2043 \mathrm{~kg} / \mathrm{m}^{3}\right)$ than that reported in Silva et al. [14], while the average compaction water content was slightly lower (9.1\%) than that in Silva et al. [14] (10.4\%).

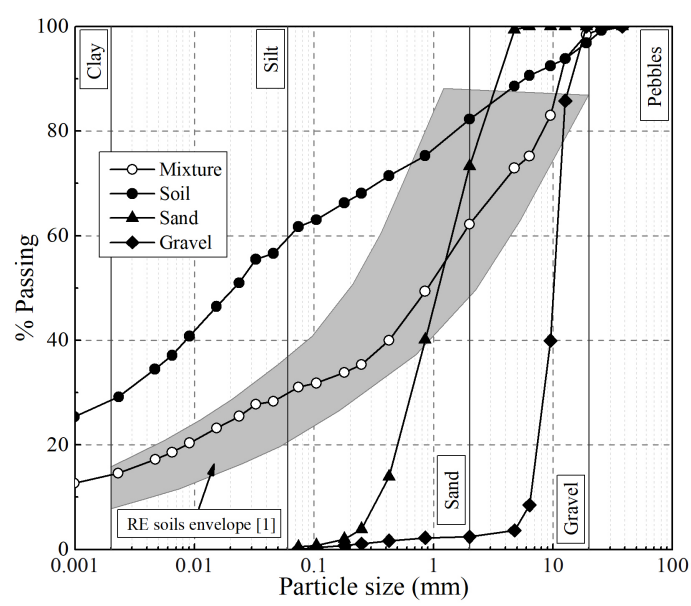

Fig. 1 - Particle size distribution curves of the raw materials used to build the rammed earth specimens. 
142 Additionally, six cylindrical specimens (100 mm diameter and $200 \mathrm{~mm}$ height) were manufactured to assess the

143 compressive behaviour of the rammed earth. These specimens were compacted in three layers $67 \mathrm{~mm}$ thick, with

144 a dry density comparable to that of the wallets (average value of $2065 \mathrm{~kg} / \mathrm{m}^{3}$ ).

\section{$146 \quad 2.2$ Testing procedures}

147 The cylindrical specimens were tested under axial compression, while the wallets were subjected to diagonal 148 compression and sonic tests. The procedures used to perform the destructive and non-destructive tests are 149 described below.

\subsubsection{Destructive tests}

151 The axial compression tests were carried out on the cylindrical specimens after a drying period of about 1529 months in controlled ambient conditions, with temperature of $20 \pm 1^{\circ} \mathrm{C}$ and relative humidity of $57.5 \pm 2.5 \%$. The 153 compression load was applied by means of a servo-controlled actuator under displacement control at a constant 154 displacement rate of $0.003 \mathrm{~mm} / \mathrm{s}$ and the axial deformations at the middle third were measured by means of three 155 LVDTs disposed radially (see Fig. 2a). This testing procedure aimed at obtaining the compressive stress-strain 156 responses, as well as the compressive strength and the Young's modulus of the rammed earth.

157 The wallets were tested under diagonal compression according to the ASTM E 519 procedure [49], using a 158 servo-controlled actuator to apply a displacement controlled load at a constant displacement rate of $0.002 \mathrm{~mm} / \mathrm{s}$ 159 (see Fig. 2b). The deformations at one of the faces of the wallets were monitored by means of LVDTs attached 160 to the middle third of each diagonal. The LVDTs were attached using the metallic apparatus illustrated in Fig. $1612 \mathrm{~b}$, fixed by the extremities to the rammed earth with hot glue. The deformations at the opposite face were 162 monitored using digital images taken sequentially from the surface, which were subsequently processed adopting 163 a DIC procedure. This procedure involved the previous creation of a stochastic black paint speckle pattern at the 164 specimen's surface, applied in a very thin layer of low water content white paint in order to minimize the 165 disturbance of the moisture conditions at the specimen's surface. The camera sensor consisted of a full frame 166 CMOS with 36 Mpix and an objective lens with a focal length of $35 \mathrm{~mm}$ and an aperture of f11, which 167 photographed the surface of the wallets every $30 \mathrm{~s}$. It should be noted that this technique constitutes an accurate 168 procedure to acquire the full-field surface displacements by comparing digital images of the object during the 169 loading process. Furthermore, the post-processing of these images assuming the material as a continuum allows 170 to obtain surface deformation maps [50]. The diagonal compression tests were aimed at characterising the 
stiffness, strength, stress-strain response and the failure mode of the rammed earth under shear loading, considering both the undamaged and repaired conditions. Thus, the wallets were tested twice. In the first time, wallets were tested after the above mentioned period of about 9 months, while in the second time they were tested about 28 days after being repaired with grout injection. During both periods the wallets were stored in the laboratory, where the temperature and the relative humidity were not actively controlled.

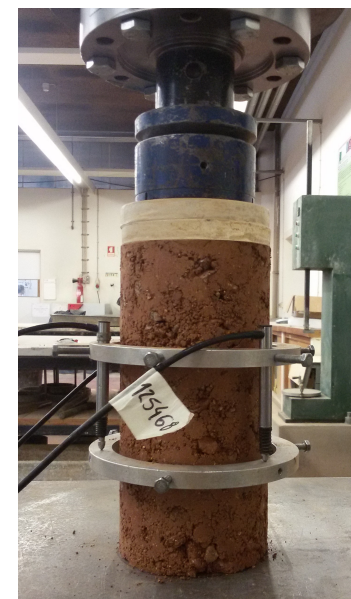

(a)

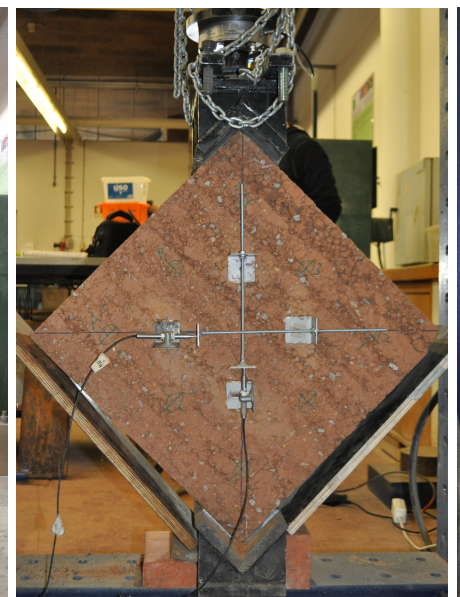

176 Fig. 2 - Setups of the destructive tests: (a) axial compression tests; (b) diagonal compression tests seen from the

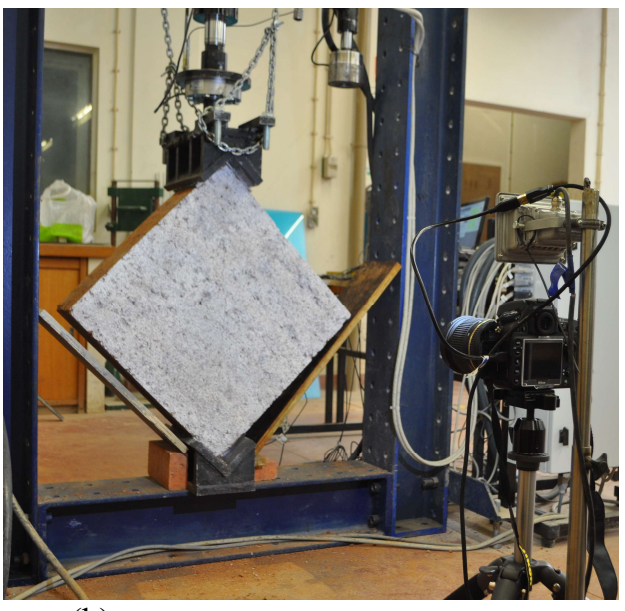

(b) LVDTs measurement surface (left) and DIC measurement surface (right).

\subsubsection{Sonic tests}

180 The test equipment used for performing the sonic tests is illustrated in Fig. 3a and consists of an instrumented 181 hammer for inducing an initial sonic pulse (20 Hz to $20 \mathrm{kHz})$, a piezoelectric accelerometer to measure the 182 arrival of the pulse, an acquisition unit from National Instruments with acquisition rate of $100 \mathrm{kHz}$ and a 183 computer with a software developed at University of Minho for acquisition and analysis of the results. Direct and 184 indirect sonic tests were performed for all wallets, as illustrated in Fig. 3b. Direct tests were performed for three 185 horizontal alignments (A, B and C) with a length of about $550 \mathrm{~mm}$, where the pulse was generated in one of the 186 edges and the arrival was measured at the opposite edge. Indirect tests were performed on one selected face of 187 the wallets using a grid composed of three horizontal alignments ( $a, b$ and $c)$ and three vertical alignments (1, 2 188 and 3). The length of each alignment was of about $350 \mathrm{~mm}$. The velocity of the P-waves $\left(V_{P}\right)$ depends on the 189 distance between the point of impact of the hammer and the point of measurement of the arrival of the pulse $(s)$,

190 and is computed according to eq. (1). It should be noted that six valid tests were considered to compute the 191 average arrival time of the P-waves $(\Delta t)$ in each alignment. 


$$
V_{p}=\frac{s}{\Delta t}
$$

192

193 The main objective of the sonic tests was to evaluate the quality of the injection repair (capacity of re-

194 establishing material continuity and bond) by measuring $V_{P}$ before the first diagonal compression test and after

195 the repair. Furthermore, the sonic tests allowed to evaluate the dynamic Young's modulus in two main directions

196 of the rammed earth (i.e. parallel and perpendicular to the compaction layers). The dynamic Young's modulus

$197\left(E_{d}\right)$ was computed using Equation (2) [51]:

198

199

200 where $\rho$ is the bulk density and $v$ is the dynamic Poisson's ratio of the rammed earth.

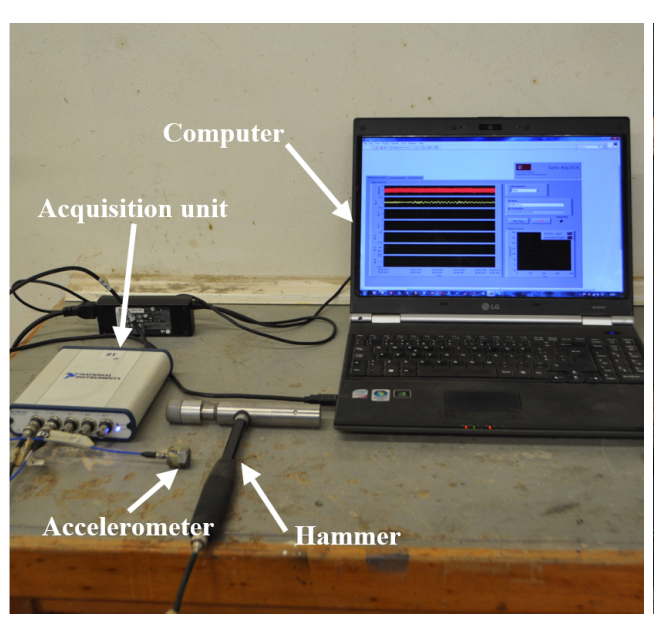

(a)

$$
E_{d}=\rho V_{p}^{2} \frac{(1+v)(1-2 v)}{(1-v)}
$$

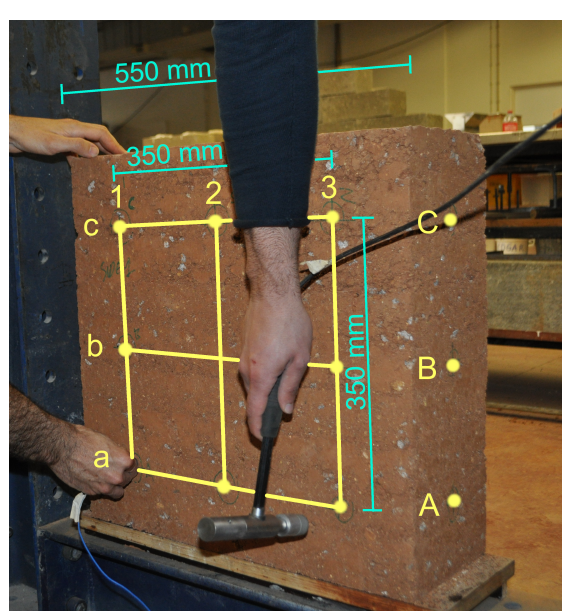

(b)

201 Fig. 3 - Sonic tests: (a) overview of the testing equipment; (b) tested alignments.

\subsection{Repair procedure}

204 After the first series of diagonal compression tests, the wallets presented main cracks that divided them into 3-6 parts, which were removed from the testing apparatus and remounted together. Then, the cracks were sealed with an earth-based mortar prepared with the soil used to build the wallets, previously sieved to remove the particles

207 larger than $4.75 \mathrm{~mm}$. Injection tubes made of flexible transparent plastic with $6 \mathrm{~mm}$ diameter were installed in 208 one of the sides of the specimens. The tubes were embedded as deep as $4 \mathrm{~cm}$ from the surface and their spacing was inferior to $10 \mathrm{~cm}$. Before conducting the injection, the sealing mortar was left to dry for more than one day.

210 A syringe with $100 \mathrm{ml}$ capacity was used to perform the grout injection, but before that, it was used to inject 
$211100 \mathrm{ml}$ of water in each injection tube in order to mitigate water sorption from the grouts to the rammed earth

212 material. The injection of the grouts was performed one hour after the injection of the water, starting from the

213 bottom tube up to the top one. Grout leakage from an adjacent injection tube dictated the sealing of the tube

214 being injected and the continuation of the process through the leaking tube. It should be noted that the width of

215 the injected cracks was observed visually to vary between $1 \mathrm{~mm}$ and $10 \mathrm{~mm}$. Furthermore, the repaired wallets

216 presented similar dimensions to those in undamaged condition. The repair procedure is illustrated in Fig. 4.

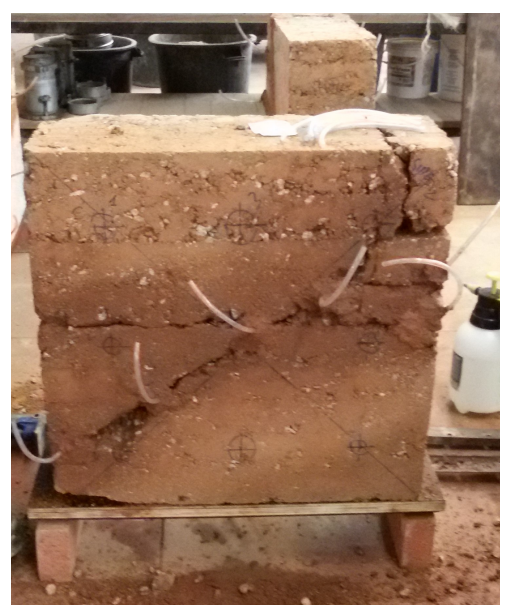

(a)

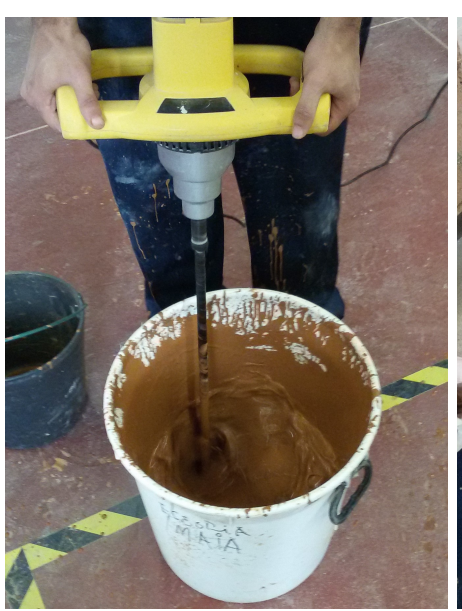

(b)

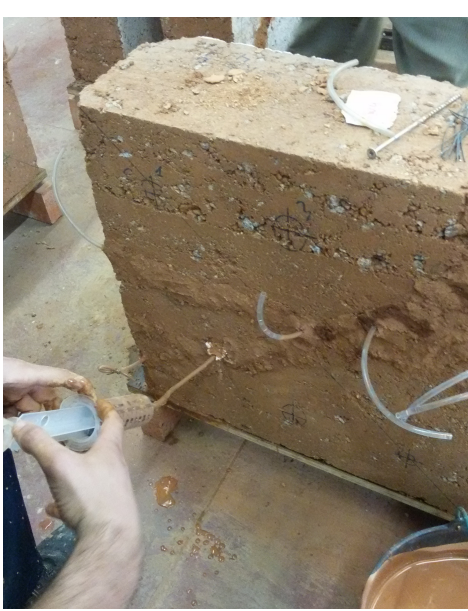

(c)

217 Fig. 4 - Repair procedure: (a) installation of the injection tubes and sealing of the cracks; (b) mixing of the clay218 based grout; (c) grout injection.

220 Three wallets were repaired using grout UCG, and other three wallets were repaired using grout FB790. UCG 221 consists of an unstabilised clay-based grout previously studied in Silva et al. [14] (mud grout B) and is composed 222 of the same soil used to build the rammed earth wallets, which was previously wet sieved to remove the particles 223 larger than $0.180 \mathrm{~mm}(\mathrm{~S} \# 80)$. This grout incorporated limestone powder (200-OU) as a filler material to reduce 224 the clay content of the sieved soil to a value of about $21 \%$ (see Fig. 5 for particle size distribution), while sodium 225 hexametaphosphate (HMP) was used to obtain adequate fluidity and low water/solids ratio (W/S). FB790 is a 226 commercial grout provided by Fassa Bortolo and is composed of hydraulic lime (NHL 3.5) and graded fillers, 227 including pozzolanic materials. The manufacturer specifies the use of this grout in the consolidation of historical 228 masonry due to its enhanced durability and compatibility. Tap water was used in the mixing of both grouts, 229 which was performed by adding the solid fraction to the water and then by mixing with a hand mixer for about $2305 \mathrm{~min}$. The compositions of both grouts and their main properties are summarised in Table 1, in terms of flow 231 time of $1 \mathrm{dm}^{3}$ (ASTM C 939 [52]), average flexural strength $\left(f_{b}\right)$ and average compressive strength $\left(f_{c}\right)$ 232 (EN 1015-11 [53]). The specimens used to evaluate the mechanical properties of the grouts were casted during 233 the repair process and were stored next to the wallets. The tests were conducted during the second series of 
234 diagonal compression tests, meaning that the grout specimens were tested at about 28 days after casting.

235 Regarding the composition, it is worth to highlight that both grouts present similar low values of W/S, which

236 resulted in similar flow time values. In terms of flexural strength, grout UCG was found to be about 2.6 times weaker than grout FB790 and 2.9 times weaker regarding the compressive strength. This difference can possibly 238 increase with time, as a relevant hardening of grout FB790 is expected to occur after the testing age, since it is composed of hydraulic lime. Few works report the mechanical properties of clay-based grouts used to repair earthen materials [14][42], nevertheless the flexural strength is found to vary in the range $0.9-1.3 \mathrm{~N} / \mathrm{mm}^{2}$ and the compressive strength in the range $2.2-2.5 \mathrm{~N} / \mathrm{mm}^{2}$, which are values relatively similar to those of UCG. On the other hand, grout FB790 is found to be relatively stronger than that studied in Müller et al. [43] (flexural strength of $0.5 \mathrm{~N} / \mathrm{mm}^{2}$ and compressive strength of $4.7 \mathrm{~N} / \mathrm{mm}^{2}$ ).

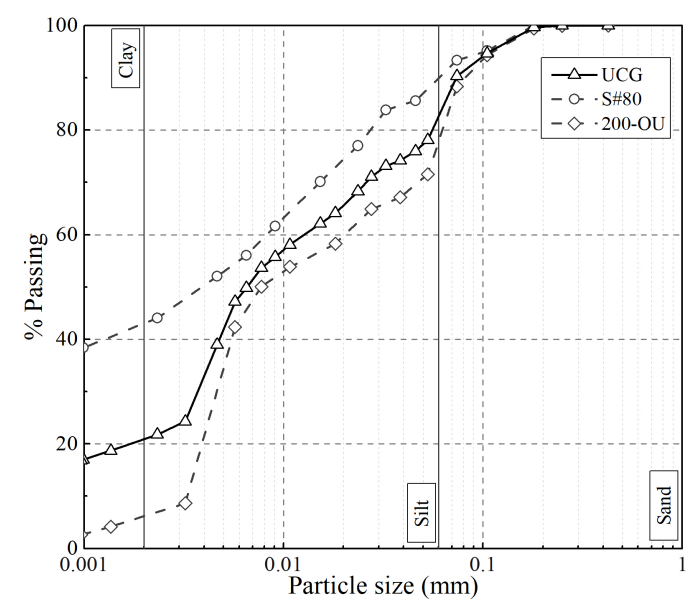

Fig. 5 - Particle size distribution curves of the materials used in grout UCG.

Table 1 - Composition of the grouts and main properties ( $\mathrm{CoV}$ is given inside parenthesis).

\begin{tabular}{|c|c|c|c|c|c|c|c|c|}
\hline \multirow[b]{2}{*}{ Grout } & \multicolumn{5}{|c|}{ Composition } & \multicolumn{3}{|c|}{ Properties } \\
\hline & $\begin{array}{c}\text { S\#80 } \\
\text { (wt.\%) }\end{array}$ & $\begin{array}{c}200-O U \\
\text { (wt.\%) }\end{array}$ & $\begin{array}{l}\text { HMP } \\
\text { (wt.\%) }\end{array}$ & $\begin{array}{l}\text { FB790 } \\
\text { (wt.\%) }\end{array}$ & $\mathrm{W} / \mathrm{S}$ & $\begin{array}{c}\text { Flow time } \\
\text { (s) }\end{array}$ & $\begin{array}{c}f_{b} \\
\left(\mathrm{~N} / \mathrm{mm}^{2}\right)\end{array}$ & $\begin{array}{c}f_{c} \\
\left(\mathrm{~N} / \mathrm{mm}^{2}\right)\end{array}$ \\
\hline UCG & 40 & 60 & 0.46 & - & 0.3 & 42 & $1.4(12 \%)$ & $3.0(16 \%)$ \\
\hline FB790 & - & - & - & 100 & 0.33 & 44 & $3.5(6 \%)$ & $8.5(8 \%)$ \\
\hline
\end{tabular}

\section{RESULTS AND DISCUSSION}

250 The results of the experimental program are presented and discussed in the following sections with respect to the 251 typology of performed tests, namely destructive and non-destructive tests. 


\subsection{Destructive tests}

254 The results of the axial compression tests are presented in Fig. 6a in terms of stress-strain curves, evidencing an 255 expressive non-linear behaviour and scattering of the deformation behaviour of the rammed earth, as reported in 256 Silva et al. [7]. An average compressive strength value of $1.5 \mathrm{~N} / \mathrm{mm}^{2}(\mathrm{CoV}=9 \%)$ was obtained and the Young's 257 modulus, computed by linear fitting of the stress-strain curves in the range $5 \%-30 \%$ of the compressive strength, 258 was of $572 \mathrm{~N} / \mathrm{mm}^{2}(\mathrm{CoV}=18 \%)$. It should be noted that the average bulk density of the specimens was of about $2592090 \mathrm{~kg} / \mathrm{m}^{3}(\mathrm{CoV}<1 \%)$ and the equilibrium water content, evaluated after the compression tests [48], was of 260 about $0.8 \%(\mathrm{CoV}=6 \%)$. In comparison with Silva et al. [14], the strength values are just slightly higher. The 261 minimum value obtained was of about $1.24 \mathrm{~N} / \mathrm{mm}^{2}$, meaning that the results deem with the minimum required 262 compressive strength prescribed in NZS 4298 [47] for standard grade rammed earth constructions, namely $2631.14 \mathrm{~N} / \mathrm{mm}^{2}$ (after applying the height/ thickness correction). On the other hand, the Young's modulus was found 264 to be half of that obtained previously, probably as a result of the variability associated to this parameter. It should 265 be highlighted that this parameter was computed in both works using the same procedure, and that the average 266 bulk density and equilibrium moisture content of the respective specimens were very similar (respectively, $2672070 \mathrm{~kg} / \mathrm{m}^{3}$ and $1 \%$ in the case of Silva et al. [14]). The Young's modulus of earthen materials is a parameter of 268 uncertain definition due to their intrinsic non-linear behaviour. For instance, Fig. $6 \mathrm{~b}$ presents the secant Young's 269 modulus of the specimens as function of the axial strain, whose relationship apparently follows a power law.

270 This behaviour is later discussed with respect to results of the sonic tests.

271 The results of the diagonal compression tests are presented in Table 2 for each wallet in terms of dry density $272\left(\rho_{d}\right)$, equilibrium water content after the first $\left(W_{\text {eq }}\right)$ and second test $\left(W_{\text {eq2 }}\right)$ [48], volume of injected grout $\left(V_{g}\right)$, 273 shear strength $\left(f_{s l}\right)$ and shear modulus $\left(G_{01}\right)$ in the first test, shear strength $\left(f_{s 2}\right)$ and shear modulus $\left(G_{02}\right)$ in the 274 second test, as well as in terms of shear strength recovery ratio $\left(f_{s 2} / f_{s l}\right)$ and shear modulus recovery ratio $275\left(G_{02} / G_{01}\right)$. The shear modulus values were computed by linear fitting of the shear stress-strain curve of each 276 specimen (see Fig. 7) at 5\% to $30 \%$ of their shear strength. It should be noted that due to technical issues, it was 277 not possible to obtain the shear stress-strain curve of specimen WURE_6 in the first series of tests. The wallets 278 were labelled as WURE_\#, where WURE means "wallet - unstabilised rammed earth" and \# is the number of the 279 specimen. 


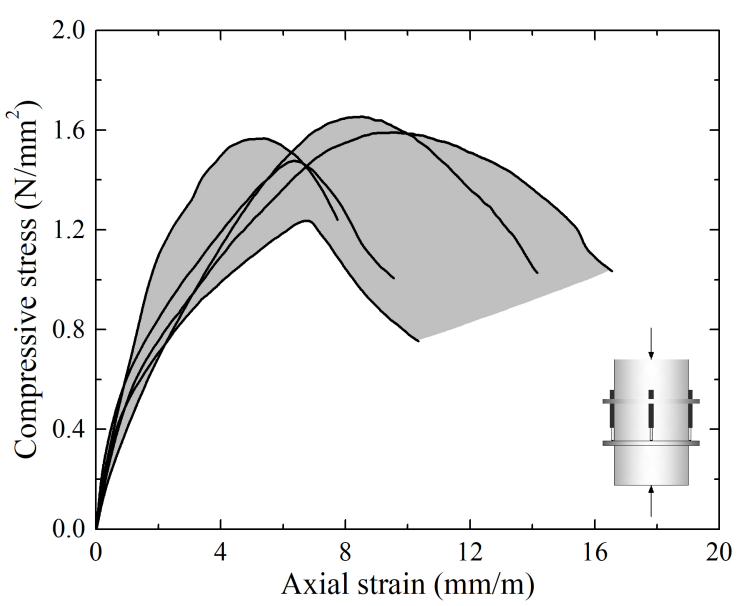

(a)

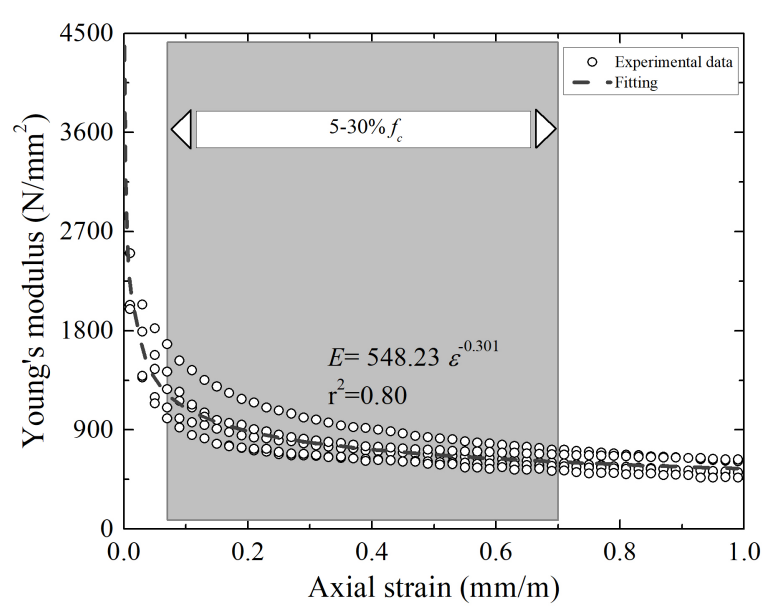

(b)

280 Fig. 6 - Results of the axial compression tests: (a) stress-strain curves; (b) variation of the secant Young's

281 modulus with the deformation level.

283 Table 2 - Results of the first and second series of diagonal compression tests.

\begin{tabular}{l|ccccccccccc}
\hline Specimen & Grout & $\begin{array}{c}\rho_{d} \\
\left(\mathrm{~kg} / \mathrm{m}^{3}\right)\end{array}$ & $\begin{array}{c}W_{\text {eq } 1} \\
(\%)\end{array}$ & $\begin{array}{c}W_{\text {eq } 2} \\
(\%)\end{array}$ & $\begin{array}{c}V_{g} \\
\left(\mathrm{dm}^{3}\right)\end{array}$ & $\begin{array}{c}f_{s 1} \\
\left(\mathrm{~N} / \mathrm{mm}^{2}\right)\end{array}$ & $\begin{array}{c}f_{s 2} \\
\left(\mathrm{~N} / \mathrm{mm}^{2}\right)\end{array}$ & $\begin{array}{c}f_{s 2} / f_{s 1} \\
(\%)\end{array}$ & $\begin{array}{c}G_{01} \\
\left(\mathrm{~N} / \mathrm{mm}^{2}\right)\end{array}$ & $\begin{array}{c}G_{02} \\
\left(\mathrm{~N} / \mathrm{mm}^{2}\right)\end{array}$ & $\begin{array}{c}G_{02} / G_{01} \\
(\%)\end{array}$ \\
\hline WURE_1 & UCG & 2053 & 0.93 & 0.98 & 2.2 & 0.12 & 0.05 & 42 & 1056 & 148 & 14 \\
WURE_2 & UCG & 2036 & 0.93 & 0.88 & 3.1 & 0.17 & 0.08 & 47 & 632 & 130 & 21 \\
WURE_3 & UCG & 2036 & 0.94 & 0.86 & 1.2 & 0.13 & 0.07 & 54 & 1068 & 94 & 9 \\
\hline Average & - & 2042 & 0.93 & 0.91 & 2.2 & 0.14 & 0.06 & 48 & 919 & 124 & 15 \\
CoV (\%) & - & 1 & 0.5 & 7 & 44 & 14 & 18 & 13 & 22 & 22 & 41 \\
\hline WURE_4 & FB790 & 2037 & 1.07 & 1.01 & 1.6 & 0.16 & 0.07 & 44 & 1356 & 99 & 7.3 \\
WURE_5 & FB790 & 2047 & 1.01 & 0.95 & 1.3 & 0.13 & 0.07 & 54 & 460 & 22 & 4.8 \\
WURE_6 & FB790 & 2048 & 0.91 & 0.90 & 1.4 & 0.12 & 0.07 & 58 & - & 34 & - \\
\hline Average & - & 2044 & 1.00 & 0.95 & 1.4 & 0.14 & 0.07 & 52 & 908 & 52 & 6 \\
CoV (\%) & - & 0 & 8 & 5 & 11 & 14 & 2 & 14 & - & 81 & - \\
\hline
\end{tabular}

285 Before discussing the shear behaviour of specimens, it is important to highlight that their equilibrium water 286 contents correspond to very low values (about 1\%), being very similar in both test series. Furthermore, and considering the volume of injected grout $\left(1.2-3.1 \mathrm{dm}^{3}\right)$ and length of the injected cracks $(1.1-1.6 \mathrm{~m})$, the average width of the injected cracks can be estimated as $6 \mathrm{~mm}$.

289 The shear behaviour of the rammed earth wallets within the first series of tests are characterised by an early peak 290 shear stress followed by a pronounced stiffness loss, see stress-strain curves in Fig. 7. In the pre-peak phase, the 291 wallets exhibit an apparent linear behaviour that is disrupted by the initiation of the first cracks, which were 292 observed to have correspondence in both faces of the wallets, indicating that they developed in full thickness. It 293 should be noted that the binding promoted by the porous structure is lost with cracking, meaning that the 294 observed early peak corresponds to the loss of the suction contribution for the shear behaviour of the wallets. 295 From this point onwards, the shear behaviour relies only on the friction and interlocking promoted by the coarse particles at the cracks, which are responsible for the large shear deformation capacity presented by the wallets. In 
the majority of the cases, the post-peak phase behaviour is characterised by a slight hardening, while two of the wallets exhibited a slight softening. The large shear deformation capacity observed in the wallets is expected to promote a large energy dissipation capacity during a seismic event. In terms of average shear strength, the wallets present a value of $0.14 \mathrm{~N} / \mathrm{mm}^{2}$, which is basically the same reported in Silva et al. [14] $\left(0.15 \mathrm{~N} / \mathrm{mm}^{2}\right)$. Furthermore, this value was found to be higher than the value reported for unstabilised rammed earth in Yamín Lacouture et al. [8], but substantially lower than the value reported in Miccoli et al. [5]. The fact is that the shear strength values obtained from diagonal compression tests available in the literature present a large dispersion, which is a direct consequence of the diversity of soils and mixtures used for rammed earth construction. However, a linear relationship can be found with respect to the reported compressive strength values, as illustrated in Fig. 8a. The average shear stiffness computed from the first series of tests is of $914 \mathrm{~N} / \mathrm{mm}^{2}$, a value higher than that reported in Silva et al. [14] $\left(646 \mathrm{~N} / \mathrm{mm}^{2}\right)$, although it should be noted that this parameter is typically affected by high variability. The range of shear modulus values reported in the literature is also found to be wide, though Fig. $8 \mathrm{~b}$ seems to show a consistent relationship of this parameter with the compressive strength. It is noteworthy to mention that the relationships presented could benefit from further testing and additional results, since the available data is limited.

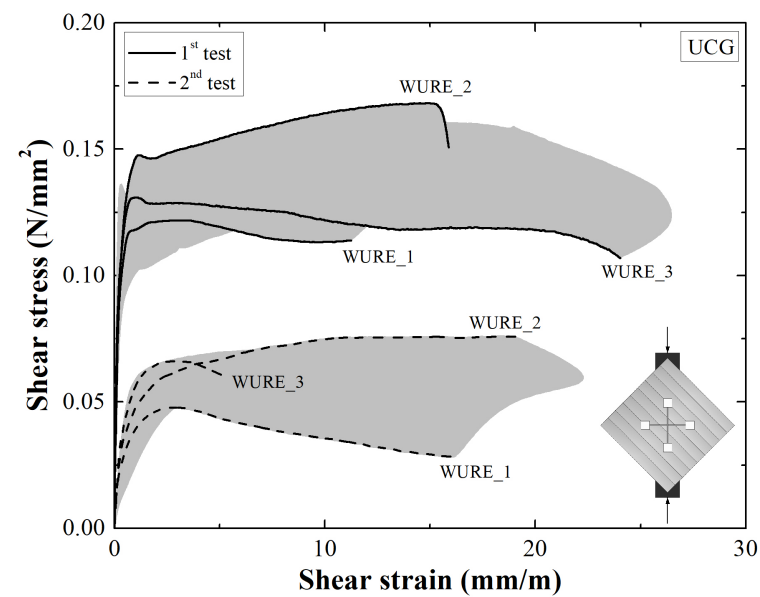

(a)

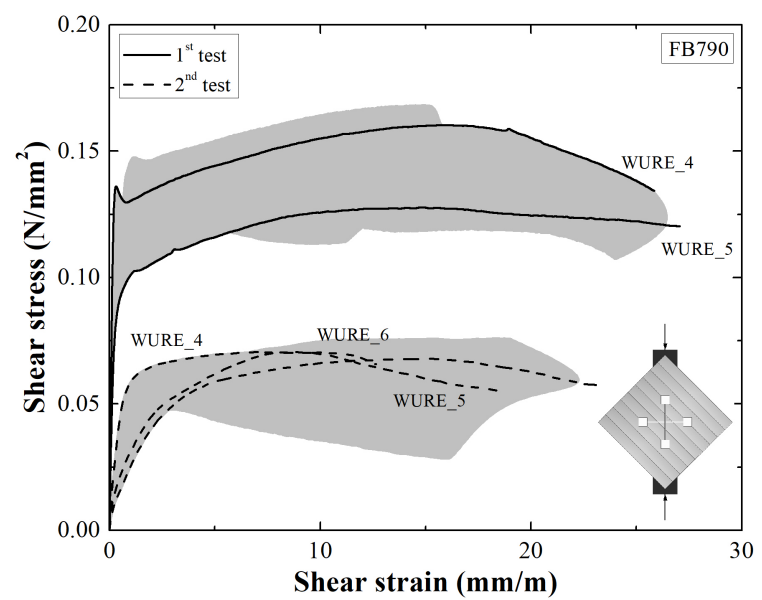

(b)

312 Fig. 7 - Shear stress-strain curves of the first and second series of diagonal compression tests: (a) wallets 313 repaired with UCG; (b) wallets repaired with FB790.

315 The development of the cracking process and failure mechanism was documented using DIC and can be 316 observed in Fig. 9 for wallets WURE_3 and WURE_4, before and after repairing. The development of the crack 317 pattern was represented by the evolution of the maximum (tensile) principal strains computed from the analysis 318 of the surface displacements obtained from the DIC procedure. Stage [A] identifies, in the shear stress-strain 319 responses, approximately the point at which the main diagonal crack initiates at the centre of the specimen, while 
stage $[B]$ is associated to the point at which the maximum shear stress is reached, and stage $[C]$ identifies the

321 point at which failure is reached. The initiation of the main diagonal crack in the first series of tests occurred just 322 before the early peak shear stress at the middle of the wallets was attained. After this stage, the main diagonal crack developed very rapidly towards the supports, though the shear stress levels remained high or even 324 increased due to the contribution of friction and interlocking mechanisms. The layered structure of the rammed earth is also shown to affect the shear behaviour of wallet WURE_3, as several cracks originated at the interfaces between layers. This situation seems to indicate that the bond between layers is particularly weak in this wallet. In the case of wallet WURE_4, a few cracks were formed also at the interfaces between layers, but these occurred at a later stage of the loading sequence.

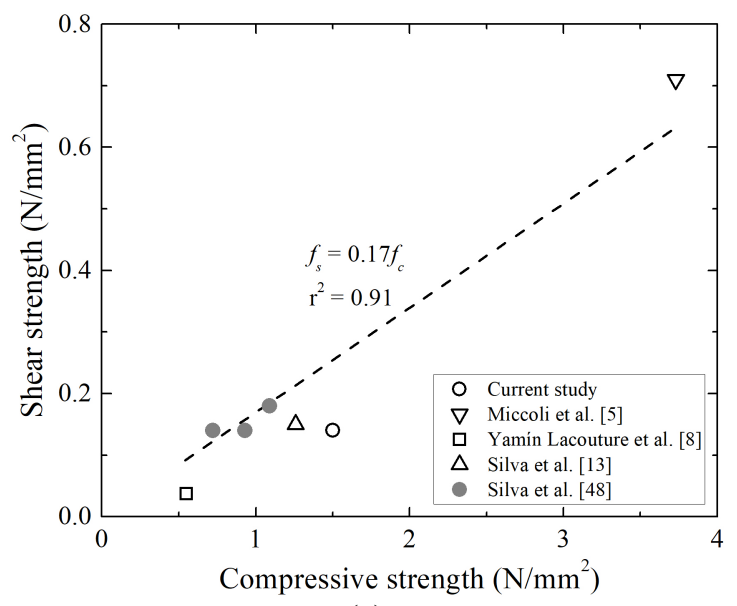

(a)

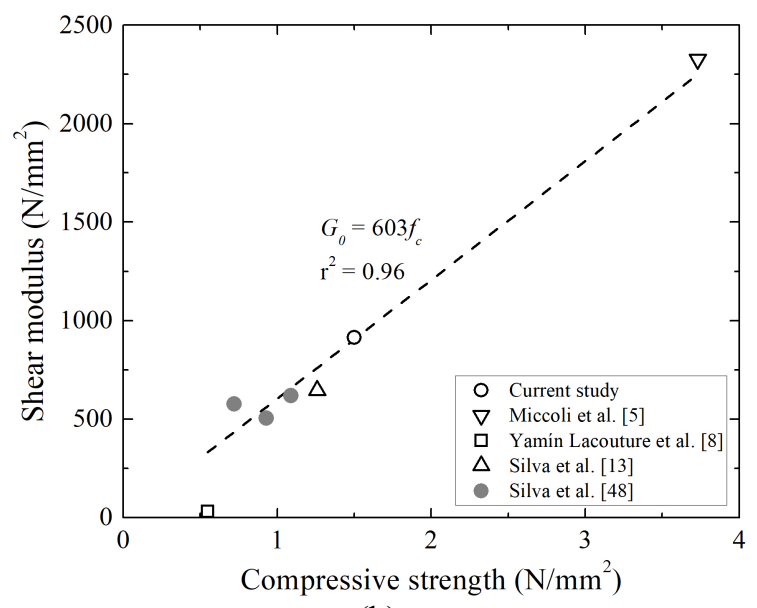

(b)

329 Fig. 8 - Relationship between compressive strength and parameters obtained from diagonal compression tests:

330 (a) shear strength; (b) shear modulus. (unstabilised rammed earth: empty points / stabilised rammed earth: filled 331 points)

333 In regard to the second series of diagonal compression tests, the wallets injected with the grout UCG presented 334 an average shear strength of about $0.06 \mathrm{~N} / \mathrm{mm}^{2}$, which corresponds to a recovery ratio of about $48 \%$. The wallets repaired with grout FB790 achieved an average shear strength of $0.07 \mathrm{~N} / \mathrm{mm}^{2}$, and thus a strength recovery ratio 336 of about $52 \%$. These results show that a similar repair effectiveness was observed in both cases, indicating that 337 the commercial hydraulic lime-based and the unstabilised clay-based grouts are essentially similar in terms of 338 strength recovery. On the other hand, the repair effectiveness of grout UCG was found to be inferior to that 339 reported in Silva e al. [14] when using the same grout composition (grout B), where a recovery ratio of about $34066 \%$ was obtained. This difference can be probably associated to a larger variability of results obtained in this 341 past study. Nonetheless, in both studies, the grout injection was unable to lead to the full recovery of the initial 342 shear modulus. The shear modulus of the repaired wallets decreased about one order of magnitude in comparison 
344 ratio of approximately 2.5 times higher than the one obtained with the use of grout FB790.
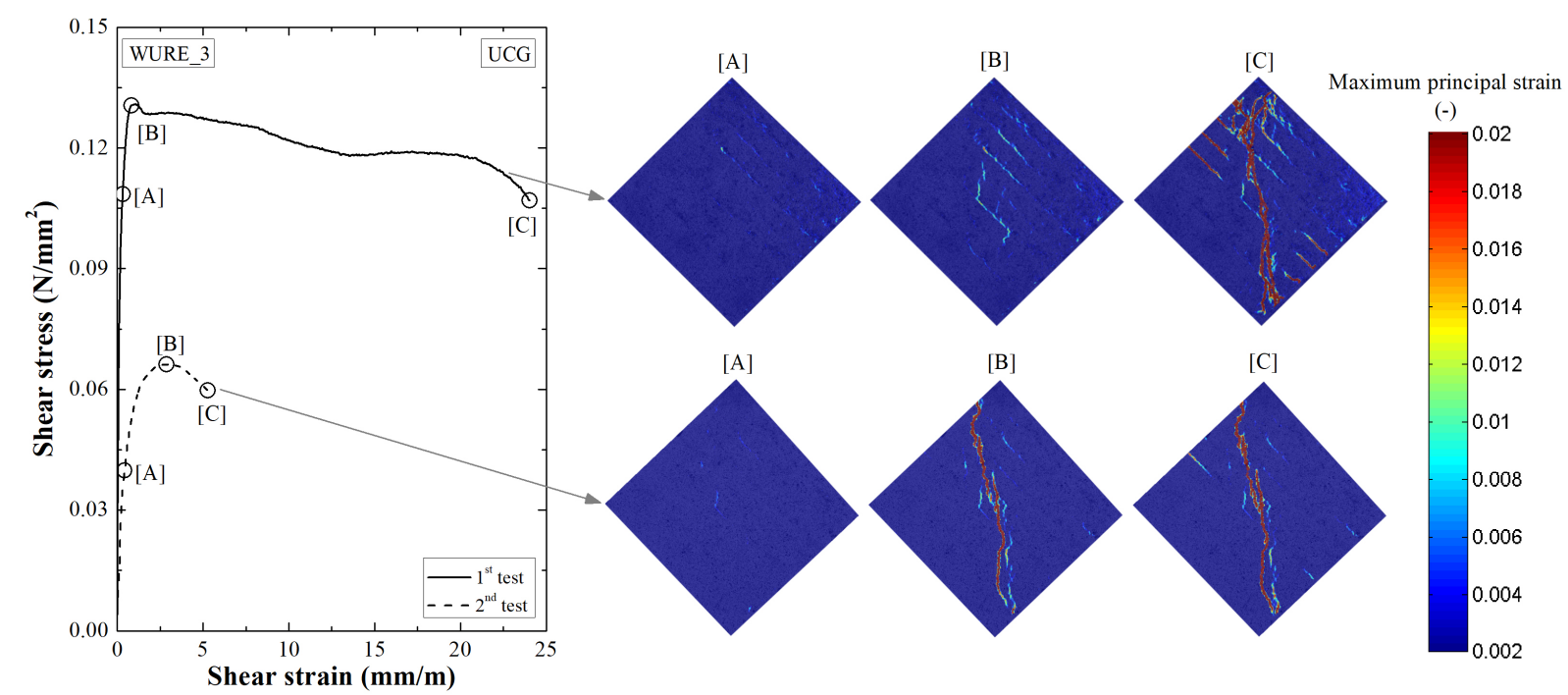

(a)
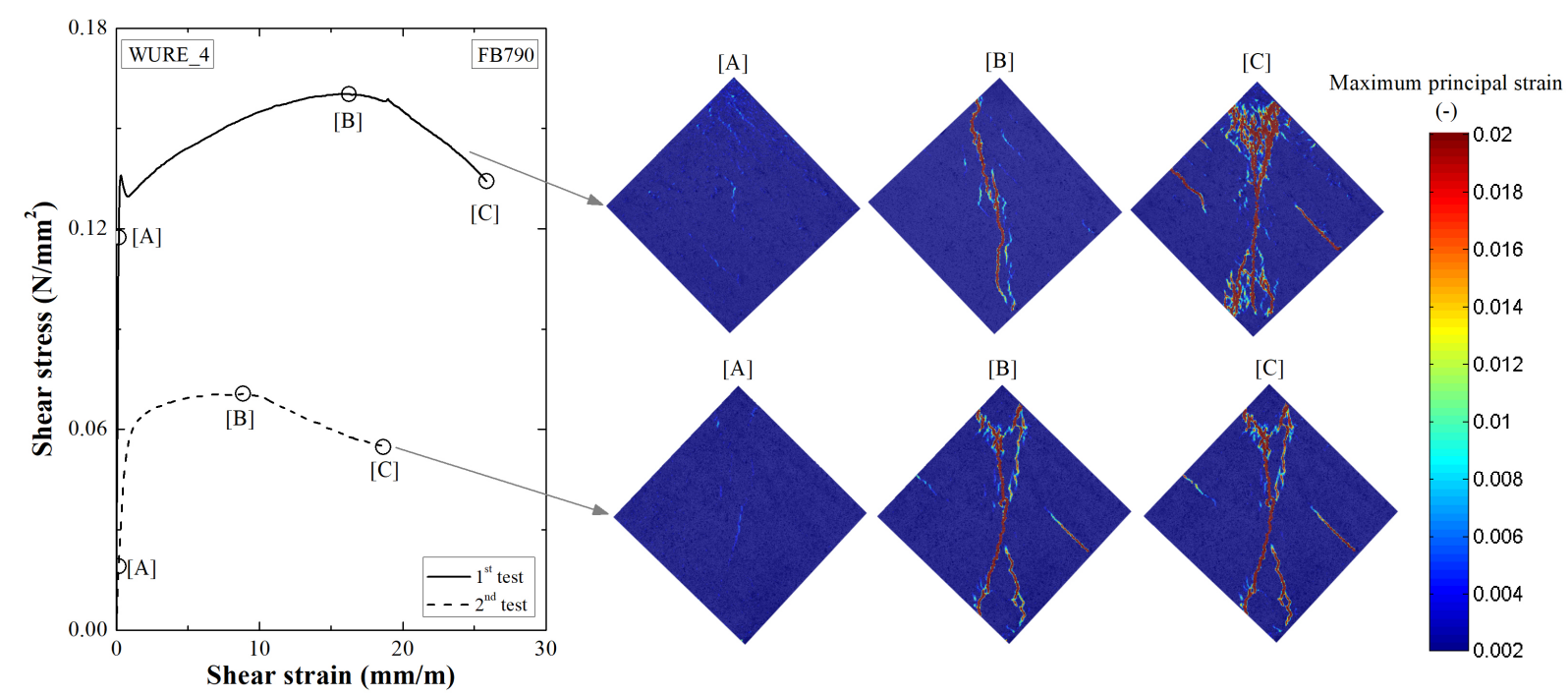

(b)

345 Fig. 9 - Evolution of the maximum principal strains of wallets: (a) WURE_3; (b) WURE_4.

347 The ability of the injection repair with any of the used grouts guarantee full recovery of the initial shear

348 performance, namely in terms of recovering the initial stiffness, was limited. This limitation results mainly from

349 the lack of reinstatement of the interlocking effect of the coarse particles at the injected crack, which originates

350 the absence of a clear early shear stress peak in the shear stress-strain curves of the second series of tests (see

351 Fig. 7), as well as a lower shear stress peak value. The failure of the wallets tested in the second series tended to

352 occur by the formation of a main diagonal crack following the path of the previously injected diagonal crack, as

353 shown in Fig. 9 by comparing the crack patterns obtained in the first and second test. Thus, the failure in the

354 second series of tests occurred by the same failure surfaces of the first series, whose roughness promoted by the 
coarse particles was extensively smoothed by the shearing imposed in the first test. Furthermore, the onset of the

356 main diagonal crack in the repaired wallets occurred at the middle of the wallets and for shear strain levels 357 similar to that of the first test, but for lower shear stresses. The observation of the repaired wallets after testing 358 allowed to detect that both grouts presented good adhesion to the rammed earth, as the grouts injected in the 359 cracks, in general, presented an adhered thin layer of rammed earth.

360 It is worthwhile to highlight that the interlocking promoted by the coarse aggregates has an important 361 contribution to the shear performance of rammed earth constructions, which are considered as monolithic 362 structures. Cracking development and crack surface smoothing decreases this contribution, which was found to 363 be unrecoverable just by injecting the cracks with grouts. On the other hand, the better repair performance of 364 grout injection used in cracked earthen masonry [42] indicates that the adhesion promoted assumes a more 365 prominent role in the shear performance. In adobe masonry, cracks are mainly formed at the joints, meaning that 366 the bond lost between the mortar and the units is the main mechanism contributing for the shear performance, 367 and is reinstated by the grout adhesion capacity.

368 In general, the injection repair alone was demonstrated to be unable to reinstate the undamaged shear 369 performance of rammed earth walls, independently of the grouts used. Thus, the incomplete repair performance 370 of the injection technique seems to reflect an intrinsic behaviour when used for rammed earth. Nevertheless, its 371 partial repair capacity may constitute a complement to other seismic strengthening intervention measures, such 372 as the strengthening with textile reinforced mortar (TRM) [55], and contribute to the overall seismic 373 strengthening of damaged structures.

\section{$375 \quad 3.2$ Sonic tests}

376 The average velocities of the P-waves obtained from the sonic tests are summarised in Table 3 according to the 377 type of grout used and test series. In general, the direct and indirect tests show good agreement with respect to 378 the estimation of the velocity in the horizontal direction (parallel to the rammed earth layers), whereby just the 379 latter are considered for further discussion.

380 In the case of the first series of tests, the velocities in the horizontal direction are significantly higher than those 381 in the vertical direction (perpendicular to the rammed earth layers), on average 1.6 times higher for all wallets. 382 The average dynamic Young's modulus was computed using Eq. (2), while assuming a bulk density equal to the 383 dry density and a dynamic Poisson's ratio $(v)$ of 0.27 . It should be noted that the bulk density was not 384 determined for the wallets because the appropriate equipment to measure their weight was unavailable. 
Regarding the Poisson's ratio, the value adopted was obtained from the experimental work presented in Miccoli et al. [56] and was also used in the numerical modelling [57] of the diagonal compression tests presented in Silva et al. [14]. Furthermore, the assumed value is within the range of Poisson's ratio values expected for dry rammed earth, namely in the range 0.1-0.3 [26][58]. The average dynamic Young's modulus value computed in the horizontal direction was of $11228 \mathrm{~N} / \mathrm{mm}^{2}(\mathrm{CoV}=25 \%)$, while that in the vertical direction was of about $4491 \mathrm{~N} / \mathrm{mm}^{2}(\mathrm{CoV}=31 \%)$, which is 2.5 times lower than the former. A similar difference is also reported in

Silva et al. [7] after a dynamic identification test on a rammed earth wall, where the dynamic Young's modulus in the horizontal direction $\left(998 \mathrm{~N} / \mathrm{mm}^{2}\right)$ was found to be 1.9 times higher than the one in the vertical direction

$393\left(515 \mathrm{~N} / \mathrm{mm}^{2}\right)$.

394 The dynamic Young's modulus in the vertical direction was also found to be about one order of magnitude higher than the Young's modulus obtained from the testing of cylindrical specimens $\left(67 \mathrm{~N} / \mathrm{mm}^{2}\right)$. This difference can be explained by the dependence of the Young's modulus on the deformation level, which can assume very high values for very low deformation values (see Fig. 6b). According to Lee et al. [59], the strain level of wave velocity methods for estimation of the elastic modulus of soils is in general inferior to $10^{-3} \sim 10^{-2} \mathrm{~mm} / \mathrm{m}$. These small levels are hardly captured with accuracy in destructive axial compression tests of soft earthen materials. It is worthwhile to mention that for a deformation value of $10^{-3} \mathrm{~mm} / \mathrm{m}$, the power law of Fig. $6 \mathrm{~b}$ results in a Young's modulus of $4384 \mathrm{~N} / \mathrm{mm}^{2}$, which is a value relatively similar to that obtained from the sonic tests in the vertical direction. Nevertheless, it should be mentioned that the definition of this power law did not take into consideration experimental data in this range of values.

Table 3 - Average velocities of the P-waves obtained from the sonic tests ( $\mathrm{CoV}$ is given inside parenthesis).

\begin{tabular}{c|cccccc}
\hline Grout set & $\begin{array}{c}V_{P d h, 1} \\
(\mathrm{~m} / \mathrm{s})\end{array}$ & $\begin{array}{c}V_{P i h, 1} \\
(\mathrm{~m} / \mathrm{s})\end{array}$ & $\begin{array}{c}V_{P i v, 1} \\
(\mathrm{~m} / \mathrm{s})\end{array}$ & $\begin{array}{c}V_{P d h, 2} \\
(\mathrm{~m} / \mathrm{s})\end{array}$ & $\begin{array}{c}V_{P i h, 2} \\
(\mathrm{~m} / \mathrm{s})\end{array}$ & $\begin{array}{c}V_{P i v, 2} \\
(\mathrm{~m} / \mathrm{s})\end{array}$ \\
\hline UCG & $2381(9 \%)$ & $2208(13 \%)$ & $1496(18 \%)$ & $2027(3 \%)$ & $2159(6 \%)$ & $1243(10 \%)$ \\
FB790 & $2826(9 \%)$ & $2726(8 \%)$ & $1646(15 \%)$ & $1635(37 \%)$ & $1551(39 \%)$ & $1056(34 \%)$ \\
\hline
\end{tabular}

$d$ : direct test / $i$ : indirect test / $h$ : horizontal direction / $v$ : vertical direction / 1: first series / 2: second series

406 Regarding the second series of tests, it can be observed that in general a reduction of the velocity of the P-waves occurs, which is particularly high in the case of the set of wallets repaired with grout FB790. In fact, the reduction of the P-waves velocities in the wallets repaired with grout UCG is found to be significantly smaller, 409 indicating that the repair procedure granted a good infill of the cracks in the wallets, which was positively observed after the second series of diagonal compression tests. On the other hand, the results of the wallets 411 repaired with grout FB790 seem to indicate the contrary. Nevertheless, the visual inspection of the wallets after the second series of diagonal compression tests showed a good infill of the cracks. Thus, this reduction is 
413 thought to be a consequence of differences in properties between the rammed earth and the grout. Finally, the

414 ratio between the velocity of the P-waves obtained from the indirect tests (average of the horizontal and vertical 415 directions) for the second and first test phase $\left(V_{P i, 2} / V_{P i, 1}\right)$, is related to the shear strength recovery ratio in Fig.

$41610 \mathrm{a}$, as well as to the shear modulus recovery ratio in Fig. 10b. Apparently no relationship seems to exist, though 417 it should be noted that the available data is somewhat limited. Thus, sonic tests do not seem to be sufficiently 418 sensitive to evaluate the effectiveness of the use of grout injection in the repair of cracks in rammed earth.

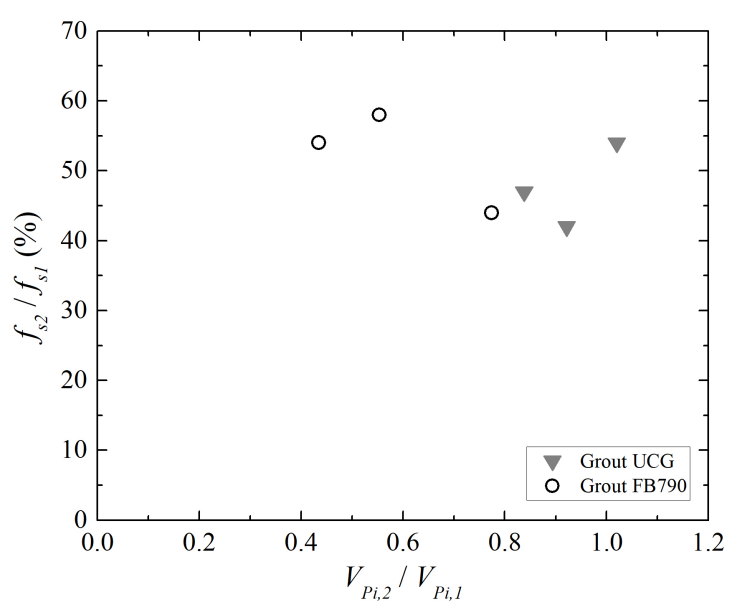

(a)

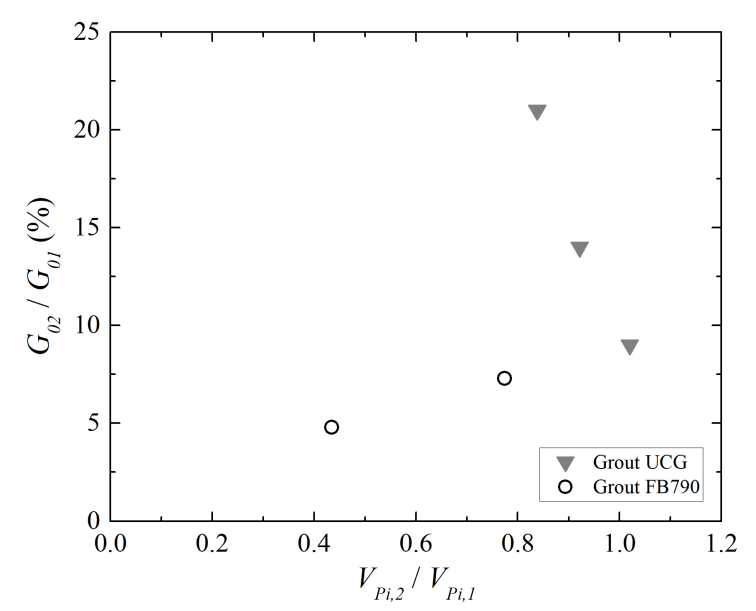

(b)

419 Fig. 10 - Relationship between the average velocity of the P-waves ratio and the: (a) shear strength recovery ratio; (b) shear modulus recovery ratio.

\section{CONCLUSIONS}

This paper presents an experimental program carried out to characterise the shear behaviour of rammed earth and assess the effectiveness of clay-based and commercial hydraulic lime-based grouts for repairing cracks in rammed earth. In this context, the results allowed to draw the conclusions summarised below:

- The clay-based grout exhibited fluidity and injectability properties similar to those of the commercial hydraulic lime-based grout, however its mechanical properties were significantly lower.

- The behaviour of rammed earth under compression is confirmed to be highly nonlinear, resulting in undefined values of the Young's modulus, as they depend deeply on the deformation level, for which a power law relationship was portrayed.

- The shear behaviour of rammed earth walls was confirmed to result from the contribution of the capillary suction promoted by the porous structure and from the friction and interlocking promoted by the coarse particles. 
- The DIC technique allowed to confirm that the early shear peak stress observed in the rammed earth wallets is preceded by the onset of the main diagonal crack, after which a fast loss of the contribution of suction for the shear behaviour is observed.

- The formation of cracks at the interfaces between layers was also evidenced by the DIC technique, highlighting that these may constitute weak surfaces influencing the shear behaviour of rammed earth walls.

- The repair effectiveness of the clay-based grout and that of the commercial hydraulic lime-based grout was shown to be similar, meaning that for compatibility reasons the former could be preferred for repair interventions. Nevertheless, it should be noted that commercial grouts seem to constitute a readily available solution with equivalent performance.

- The repair of cracks in rammed earth with grout injection was shown to be able to recover partially the shear loading capacity of the wallets, but was ineffective to re-establish the initial shear stiffness.

- The comparison of the DIC images from both series of tests showed that the cracking originated during the first series of tests and prior to repairing constituted the preferential path for the formation of the cracks during the second series of tests.

- The sonic tests revealed a relevant orthotropic behaviour of the rammed earth wallets, as the P-waves propagate faster in the direction parallel to the layers than in the perpendicular direction.

- The dynamic Young's modulus was found to be about one order of magnitude higher than the static Young's modulus of rammed earth, due to the different reference strain levels, meaning that the estimation of this parameter should be based on strain/stress levels expected in the material and should

Finally, it should be highlighted that the incomplete repair performance of the injection technique seems to be an 458 intrinsic behaviour when it is used to repair cracks in rammed earth, meaning that the seismic strengthening of these structures should mainly rely on solutions specifically developed for this purpose.

\section{ACKNOWLEDGEMENTS}

This work was partly financed by FEDER funds through the Competitivity Factors Operational Programme - 


\section{REFERENCES}

[1] Houben H., Guillaud H., Earth Construction: A Comprehensive Guide. 3rd ed. London, UK: CRATerre EAG, Intermediate Technology Publication, 2008.

[2] Jaquin P.A., Augarde C.E., Gerrard C.M., Chronological description of the spatial development of rammed earth techniques. International Journal of Architectural Heritage 2008, 2.4: 377-400.

[3] Silva R.A., Oliveira D.V., Miranda T., Cristelo N., Escobar M.C., Soares E., Rammed earth construction with granitic residual soils: The case study of northern Portugal. Construction and Building Materials 2013, 47: 181-191.

[4] Yamin L.E., Phillips C.A., Reyes J.C., Ruiz D.M., Seismic behavior and rehabilitation alternatives for adobe and rammed earth buildings. In proc. of 13th World Conference on Earthquake Engineering Conference, Vancouver, 2004.

[5] Miccoli L., Müller U., Fontana P., Mechanical behaviour of earthen materials: a comparison between earth block masonry, rammed earth and cob. Construction and Building Materials 2014, 61: 327-339.

[6] Minke G., Building with earth, design and technology of a sustainable architecture. Basel- Berlin-Boston: Birkhäuser - Publishers for Architecture, 2006.

[7] Silva R.A., Mendes N., Oliveira D.V., Romanazzi A., Domínguez-Martínez O., Miranda T., Evaluating the seismic behaviour of rammed earth buildings from Portugal: From simple tools to advanced approaches. Engineering Structures 2018, 157: 144-156.

[8] Yamín Lacouture L.E., Phillips Bernal C., Ortiz R., Carlos J., Ruiz Valencia D., Estudios de vulnerabilidad sísmica, rehabilitación y refuerzo de casas en adobe y tapia pisada. Apuntes: Revista de Estudios sobre Patrimonio Cultural-Journal of Cultural Heritage Studies 2007, 20.2: 286-303. (in Spanish)

[9] Gomes M.I., Lopes M., De Brito J., Seismic resistance of earth construction in Portugal. Engineering Structures 2011, 33.3: 932-941.

491 [11] Braga A.M., Las Construcciones de Tierra Cruda en el Algarve. Potencialidades como Material Alternativo y Sostenible. Construções em Terra Crua no Algarve. PhD thesis Spain: University of Seville, Seville, 
[12] IPQ, NP ENV 1998-1: Eurocode 8: Design of structures for earthquake resistance - Part 1: General rules, seismic actions and rules for buildings. Lisbon: Instituto Português da Qualidade, 2009.

[13] Cheah J., Walker P., Heath A., Morgan T.K.K.B., Evaluating shear test methods for stabilised rammed earth. Proceedings of Institution of Civil Engineers, Construction Materials 2012, 165.6:325-334.

[14] Silva R.A., Oliveira D.V., Schueremans L., Miranda T., Machado J., Effectiveness of the repair of unstabilised rammed earth with injection of mud grouts. Construction and Building Materials 2016,127:861-71.

[15] Nabouch R., Bui Q.B., Plé O., Perrotin P., Poinard C., Goldin T., Plassiard, J.P., Seismic assessment of rammed earth walls using pushover tests. Procedia Engineering 2016, 145:1185-92.

[16] Miccoli L., Drougkas A., Müller U., In-plane behaviour of rammed earth under cyclic loading: experimental testing and finite element modelling. Engineering Structures 2016, 125:144-52.

[17] Arslan M.E., Emiroğlu M., Yalama A., Structural behavior of rammed earth walls under lateral cyclic loading: a comparative experimental study. Construction and Building Materials 2017, 133:433-42.

[18] Jaquin P.A., Augarde C.E., Gallipoli D., Toll D.G., The strength of unstabilised rammed earth materials. Géotechnique 2009, 59.5: 487-490.

[19] Cheah J., Development of a flax-fibre reinforced, cement-stabilized rammed earth housing solution (Uku) for rural Māori communities. PhD thesis New Zealand: University of Auckland, Auckland, 2014.

[20] Ciancio D., Augarde C.. Capacity of unreinforced rammed earth walls subject to lateral wind force: elastic analysis versus ultimate strength analysis." Materials and structures 2013, 46.9:1569-1585.

[21] Gomes I., Conservação de construções de taipa: argamassas de reparação. PhD thesis Portugal,: Universidade Nova de Lisboa, Lisboa 2013. (in Portuguese)

[22] Oliveira D.V., Silva R.A., Schueremans L., Lourenço P.B., A construção em taipa e os sismos. In proc. of $8^{\circ}$ Encontro Nacional de Sismologia e Engenharia Sísmica (SÍSMICA 2010), Aveiro, 2010. (in Portuguese)

[23] Warren J., Conservation of earth structures. Butterworth-Heinemann, 1999.

[24] Morel J.C., Bui Q.B., Hamard E., Weathering and durability of earthen materials and structures. Modern earth building 2012: 282-303.

[25] Silva R.A., Jaquin P.A., Oliveira D.V., Miranda T., Schueremans L., Cristelo N., Conservation and new construction solutions in rammed earth. Structural rehabilitation of old buildings. Springer Berlin Heidelberg, 2014. 77-108. 
[26] Bui Q.B., Morel J.C., Hans S., Walker P., Effect of moisture content on the mechanical characteristics of rammed earth. Construction and Building materials 2014, 54: 163-169.

[27] Jaquin P., Augarde C., Earth building: history, science and conservation. Bracknell: IHS BRE Press, 2012.

[28] Illampas R., Ioannou I., Charmpis D.C. Overview of the pathology, repair and strengthening of adobe structures. International Journal of Architectural Heritage 2013, 7.2:165-188.

[29] Tolles E.L., Webster F.A., Crosby A., Kimbro E.E., Survey of Damage to Historic Adobe Buildings After the January 1994 Northridge Earthquake, The Getty Conservation Institute 1996, Los Angeles.

[30] Vargas J., Blondet M., Cancino C., Ginocchio F., Iwaki C., Morales K., Experimental results on the use of mud-based grouts to repair seismic cracks on adobe walls. In proc. of the 6th International Conference on Structural Analysis of Historic Constructions 2008, D’Ayala D., Fodde E. (eds), Bath.

[31] Getty, Interdisciplinary Experts Meeting on Grouting Repairs for Large-scale Structural Cracks in Historic Earthen Buildings in Seismic Areas. The Getty Conservation Institute 2007.

[32] Valluzzi M.R., Binda L., Modena C., Experimental and analytical studies for the choice of repair techniques applied to historic buildings. Materials and Structures 2002, 35.5: 285-292.

[33] Vintzileou E., Miltiadou-Fezans A., Mechanical properties of three-leaf stone masonry grouted with ternary or hydraulic lime-based grouts. Engineering Structures 2008, 30.8: 2265-2276.

[34] Kalagri A., Miltiadou-Fezans A., Vintzileou E., Design and evaluation of hydraulic lime grouts for the strengthening of stone masonry historic structures. Materials and Structures 2010, 43.8: 1135-1146.

[35] Oliveira D.V., Silva R.A., Garbin E., Lourenço P.B., Strengthening of three-leaf stone masonry walls: an experimental research. Materials and Structures 2012, 45.8: 1259-1276.

[36] Bras A., Henriques F.M., Natural hydraulic lime based grouts-The selection of grout injection parameters for masonry consolidation. Construction and Building Materials 2012, 26.1: 135-144.

[37] Luso E., Lourenço P.B., Experimental characterization of commercial lime based grouts for stone masonry consolidation. Construction and Building Materials 2016, 102:216-225.

[38] Roselund N., Repair of cracked adobe walls by injection of modified mud. In proc. of the 6th International Conference on the Conservation of Earthen Architecture 1990. New Mexico.

[39] Jäger W., Fuchs C., Reconstruction of the Sistani House at Bam Citadel after the collapse due to the earthquake 2003. In proc. of the 6th International Conference on Structural Analysis of Historic Constructions 2008, D’Ayala D., Fodde E. (eds), Bath. 
[40] Silva R.A., Schueremans L., Oliveira D.V., Dekoning K., Gyssels T., On the development of unmodified mud grouts for repairing earth constructions: rheology, strength and adhesion. Materials and Structures 2012, 45.10: 1497-1512.

555

[41] Blondet M., Vargas J., Groenenberg R.J., Evaluation of the efficacy of mud injection to repair seismic cracks on adobe structures via full-scale shaking table tests. In Proceedings of the 15th World Conference on Earthquake Engineering. Lisbon, Portugal, 24-28 September, 2012.

[42] Illampas R., Silva R.A., Charmpis D.C., Lourenço P.B., Ioannou I., Validation of the repair effectiveness of clay-based grout injections by lateral load testing of an adobe model building. Construction and Building Materials 2017,153: 174-184.

[43] Müller U., Miccoli L., Fontana P., Development of a lime based grout for cracks repair in earthen constructions. Construction and Building Materials 2016, 110: 323-332.

[44] LNEC. LNEC E 196-1966 - Solos. Análise granulométrica. Lisbon: Laboratório Nacional de Engenharia Civil, 1966. (in Portuguese)

[45] LNEC. NP 143:1969 - Solos. Determinação dos limites de Consistência. Lisbon: Laboratório Nacional de Engenharia Civil; 1969. (in Portuguese)

[46] LNEC. LNEC E 197-1966 - Solos. Ensaio de compactação. Lisbon: Laboratório Nacional de Engenharia Civil; 1966. (in Portuguese)

[47] NZS. NZS 4298: Materials and workmanship for earth building. Wellington: Standards New Zealand, 1998.

[48] LNEC. NP 143:1969 - Solos. Determinação do teor em água. Lisbon: Laboratório Nacional de Engenharia Civil; 1965. (in Portuguese)

[49] ASTM. ASTM E 519: Standard Test Method for Diagonal Tension (Shear) in Masonry Assemblages. West Conshohocken: American Society for Testing and Materials, 2002.

[50] Chu T.C., Ranson W.F., Sutton M.A., Applications of digital-image-correlation techniques to experimental mechanics. Experimental Mechanics 1985, 25.3: 232-244.

[51] BSI. BS 1881-203: Testing concrete - Part 203: Recommendations for measurement of velocity of ultrasonic pulses in concrete. London: British Standard, 1986.

[52] ASTM. ASTM C 939: Standard test method for flow of grout for preplaced-aggregate concrete (flow cone method). West Conshohocken: American Society for Testing and Materials, 1994. 
581 [53] CEN. EN 1015-11: Methods of test for mortar for masonry - Part 11: Determination of flexural and compressive strength of hardened mortar. Brussels: European Committee for Standardization, 1999.

583 [54] Silva R.A., Oliveira D.V., Miranda T., Cristelo N., Escobar M.C., Soares E., Rammed earth construction 584 with granitic residual soils: The case study of northern Portugal, Construction and Building Materials 2013, $585 \quad 47: 181-191$.

586 [55] Silva R.A., Oliveira D.V., Barroso C., Ramírez R., Pereira E., Lourenço P.B., Investigation of the bond and 587 shrinkage behaviour of TRM strengthening for rammed earth. Euro-American Congress REHABEND 588 2018: Construction Pathology, Rehabilitation Technology and Heritage Management, 15-18 May, Cáceres, 5892018.

590 [56] Miccoli L., Oliveira D.V., Silva R.A., Müller U., Schueremans L., Static behaviour of rammed earth: 591 experimental testing and finite element modelling. Materials and Structures 2015, 48: 3443-3456.

592 [57] Silva R.A., Oliveira D.V., Schueremans L., Miranda T., Machado J., Modelling of the Structural Behaviour 593 of Rammed Earth Components, Lourenço, Topping, B.H.V., Iványi, P. (eds), 12th International Conference 594 on Computational Structures Technology, 2-5 September, Naples, 2014.

595 [58] Bui Q.B., Hans S., Morel J.C., Do A.P., First exploratory study on dynamic characteristics of rammed earth buildings. Engineering Structures 2011, 33.12: 3690-3695.

597 [59] Lee I.M., Kim J.S., Yoon H.K., Lee J.S., Evaluation of compressive strength and stiffness of grouted soils 598 by using elastic waves. The Scientific World Journal 2014. 


\section{LIST OF TABLE CAPTIONS}

600

601 Table 1 - Composition of the grouts and main properties ( $\mathrm{CoV}$ is given inside parenthesis).

602 Table 2 - Results of the first and second series of diagonal compression tests.

603 Table 3 - Average velocities of the P-waves obtained from the sonic tests ( $\mathrm{CoV}$ is given inside parenthesis). 604 


\section{LIST OF FIGURE CAPTIONS}

606

607 Fig. 1 - Particle size distribution curves of the raw materials used to build the rammed earth specimens.

608 Fig. 2 - Setups of the destructive tests: (a) axial compression tests; (b) diagonal compression tests seen from the

609 LVDTs measurement surface (left) and DIC measurement surface (right).

610 Fig. 3 - Sonic tests: (a) overview of the testing equipment; (b) tested alignments.

611 Fig. 4 - Repair procedure: (a) installation of the injection tubes and sealing of the cracks; (b) mixing of the clay-

612 based grout; (c) grout injection.

613 Fig. 5 - Particle size distribution curves of the materials used in grout UCG.

614 Fig. 6 - Results of the axial compression tests: (a) stress-strain curves; (b) variation of the secant Young's

615 modulus with the deformation level.

616 Fig. 7 - Shear stress-strain curves of the first and second series of diagonal compression tests: (a) wallets

617 repaired with UCG; (b) wallets repaired with FB790.

618 Fig. 8 - Relationship between compressive strength and parameters obtained from diagonal compression tests:

619 (a) shear strength; (b) shear modulus. (unstabilised rammed earth: empty points / stabilised rammed earth: filled 620 points)

621 Fig. 9 - Evolution of the maximum principal strains of wallets: (a) WURE_3; (b) WURE_4.

622 Fig. 10 - Relationship between the average velocity of the P-waves ratio and the: (a) shear strength recovery

623 ratio; (b) shear modulus recovery ratio.

624 